\title{
Drought Characteristics for Maize and its Effect on Yield in Midwestern Jilin Province
}

\author{
Rui Wang ${ }^{1,2,3}$, Jiquan Zhang ${ }^{1,2,3, *}$, Tiehua $\mathrm{Cao}^{4}$, Xin Zhao ${ }^{4}$, Jing Zhao ${ }^{1,2,3}$, Si Alu ${ }^{1,2,3}$ \\ ${ }^{1}$ School of Environment, Northeast Normal University, Changchun 130117, China \\ ${ }^{2}$ State Environmental Protection Key Laboratory of Wetland Ecology and Vegetation Restoration \\ (Northeast Normal University), Changchun 130117, China \\ ${ }^{3}$ Key Laboratory for Vegetation Ecology, Ministry of Education (Northeast Normal University), \\ Changchun 130117, China \\ ${ }^{4}$ Jilin Academy of Agricultural Sciences, Changchun 130117, China
}

\section{吉林中西部地区玉米干旱特征及对产量的影响 \\ 王聴 ${ }^{1,2,3}$ ，张继权 ${ }^{1,2,3, *}$ ，曹铁华 ${ }^{4}$, 赵金 ${ }^{4}$, 赵静 ${ }^{1,2,3}$, 阿鲁思 ${ }^{1,2,3}$ \\ ${ }^{1}$ 东北师范大学环境学院, 长春 130117 , 中国 \\ ${ }^{2}$ 国家环境保护湿地生态与植被恢复重点实验室（东北师范大学), 长春 130117 , 中国 \\ ${ }^{3}$ 植物生态学教育部重点实验室 (东北师范大学), 长春 130117 , 中国 \\ ${ }^{4}$ 吉林省农业科学研究院, 长春 130117 , 中国}

\begin{abstract}
Maize is the main grain crop in Midwestern Jilin province. It's conducive to analyze the characteristics and the effects on maize of droughts. 9 stations were selected during 1960-2014 based on the crop water deficit index (CWDI) and drought grades. Results show that:(1) The district water deficit condition are the overall drought characteristics in study area. Serious spring drought occurred more frequently in the western region of China, and the autumn droughts in eastern region are more likely to occur. (2) there was a direct effect on maize yield by droughts in the north regions of all study area. Excepting the jointing-tasseling stages, the water deficit in the eastern region of the remaining three growing periods had little
\end{abstract}

*通讯作者: 张继权 (1965-), 教授, 博士 生导师, 主要从事环境灾害风险评价与管 理、预警等方向研究

邮箱: zhangjq022@nenu.edu.cn effect on maize yield.

Keywords: characteristics of droughts, crop water deficit index, maize, yield, midwestern Jilin province

摘要

玉米是吉林省主要粮食作物之一, 对研 究区玉米干旱的特征和干旱对产量的影响 的分析至关重要。本文选取 1960-2014 年吉 林中西部地区 9 个气象台站的气象、农业数 据, 基于水分亏缺指数（CWDI）和农业干旱 等级标准，分析吉林中西部地区玉米不同生 育期干旱特征及其对产量的影响。结果表 明：（1）全区整体为水分亏缺状态，旱情严 重。西部地区更易发生春旱，东部地区更易 发生秋旱; (2) 研究区以北受到干旱后对玉 米产量有直接的影响, 除拔节-抽雄期外, 其余三个生育期东部地区的水分亏缺对玉 米产量的影响不大。

关键词: 干旱特征; 作物水分亏缺指数; 玉 米; 产量; 吉林中西部 
1 引言

农业气象灾害的发生占据我国全部农 业自然灾害的 70\%，对农业生产、加工的影 响最为严重 $[1,2]$ 。随着全球的气候变暖现 象, 农业气象灾害的发生呈现更高频、更高 强度的趋势, 其灾害发生所造成的风险也越 来越大, 已备受国内外学者和管理者的重视 [3-5]。干旱灾害是我国对农业影响最为严 重的气象灾害之一, 是由于异常干燥的天气 所导致的水循环严重失衡现象, 它可以发生 在所有的气候区, 且持续时间一般较长。近 年来, 在气候变化的背景下, 干旱灾害的发 生范围不断扩大, 所造成的损失也逐渐加 重, 导致了作物的减产、绝产, 人口迁移等 现象, 对人们的生产生活造成了巨大的影响 [6]。据统计, 我国每年由于自然灾害成灾 面积高达 2.71 亿亩, 其中因干旱造成的成 灾面积为 1.45 亩, 占全年自然灾害成灾面 积的 $51.9 \%$ [7]。因此, 开展农业干旱灾害的 研究成为了一项重要的课题。

吉林中西部地区是中国东北的中心地 区, 也是我国主要的商品粮基地, 该地区降 水波动较大, 常发生干旱现象, 素有十年九 春旱之称 $[8]$ 。吉林中西部地区位于东北黄
金玉米带的枢纽地区, 玉米是该区域的主要 农作物, 且玉米的生长发育主要与降水有 关, 据了解吉林中西部地区由于干旱灾害的 频发, 造成玉米受早影响较大, 且大多需要 通过灌溉才能维持正常的产量, 因此对玉米 生育期的干旱特征及对产量影响的分析至 关重要。

目前, 干旱指标的研究有很多且发展的 比较成熟 [9-11]。比如标准化降水指数 (SPI)、相对湿度指数 (MI) 、综合气象干 旱指标 (CI)、水分亏缺指标 (CWDI) 等。 针对于玉米干旱的研究, 在考虑气象因素的 基础上, 还需要考虑土壤、作物本身, 综合 的分析不同生育期干旱对玉米的影响。基于 此, 本研究采用水分亏缺指数对近 55 年间 不同生长季的玉米干旱特征进行分析, 并探 究干旱灾害与玉米产量之间的关系, 以期为 当地农业管理部门提供科学的依据。

\section{2. 研究区及数据来源}

吉林省中西部地区 $\left(43^{\circ} 16^{\prime}-46^{\circ} 18^{\prime} \mathrm{N}\right.$, $121^{\circ} 38^{\prime}-127^{\circ} 45^{\prime} \mathrm{E}$ ), 位于吉林省松嫩平原的 西南端、科尔沁草原的东部, 研究区包括白 城、镇㐘、松原、四平、舒兰市等 19 个县 市 (图 1)。地势较为平坦, 属于大陆性季风

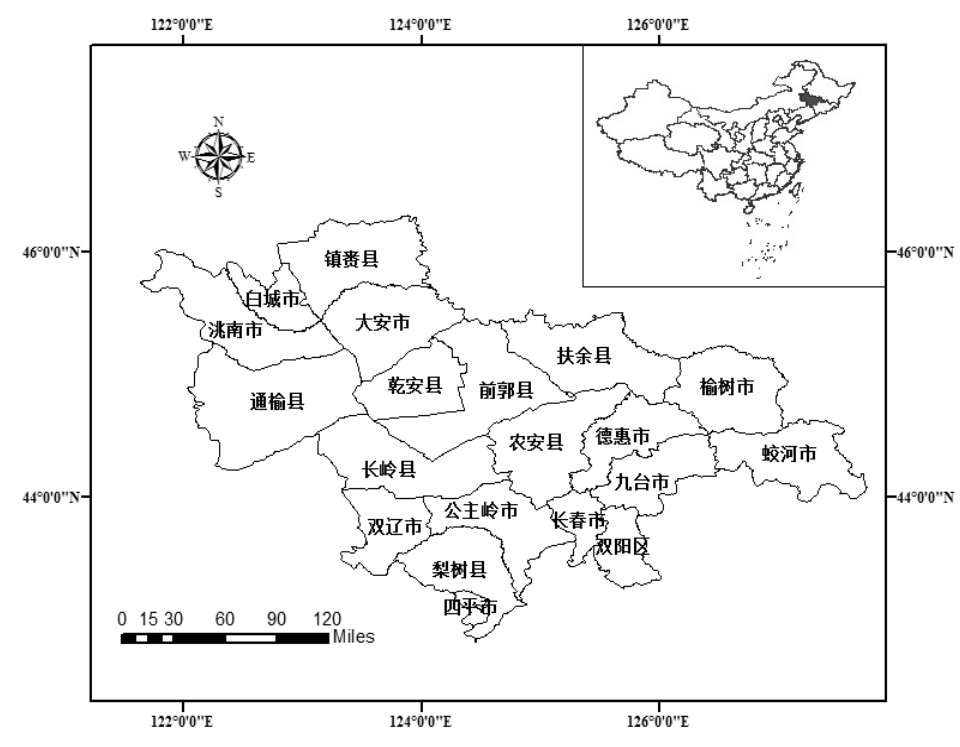

图 1 研究区地理位置图 
气候。研究区域总面积占吉林省土地面积的 $44.23 \%$ 。多年平均降水量在 $350-580 \mathrm{~mm}$ 之间, 多集中在 6-9 月, 春秋干旱少雨, 夏季炎热 多雨, 属吉林省主要干旱地区, 对玉米生产 影响较为严重。

本研究选取研究区 9 个主要的农业气象 观测站作为研究, 其中 1960-2014 年间的逐 日气象数据 (主要包括温度、降水、日照、 平均风速、平均相对湿度等) 来源于中国气 象数据共享平台, 发育期数据包括 1980-2010 年研究区出苗、拔节、抽雄、乳 熟和成熟的日期, 来源于吉林省农业站多年 统计数据, 本文利用各个站点多年平均发育 期数据, 将玉米生长期划分为出苗一拔节期、 拔节-抽雄期、抽雄-乳熟期和乳熟-成熟期 (表 1)。产量数据包括 1960-2014 年玉米的 亩产数据, 来源于中华人民共和国农业农村 部。

\begin{tabular}{|c|c|c|c|c|c|c|c|c|c|}
\hline \multicolumn{5}{|c|}{ 表 1 不同站点玉米主要发育阶段 } & & \multicolumn{4}{|c|}{$E T_{0}=\frac{T_{\text {mean }}+273}{\Delta+\gamma\left(1+0.34 U_{2}\right)}$} \\
\hline 区域 & $\begin{array}{l}\text { 出苗- } \\
\text { 拔节 }\end{array}$ & $\begin{array}{l}\text { 拔节- } \\
\text { 抽雄 }\end{array}$ & $\begin{array}{l}\text { 抽雄- } \\
\text { 乳熟 }\end{array}$ & $\begin{array}{l}\text { 乳熟- } \\
\text { 成熟 }\end{array}$ & & \multirow{4}{*}{\multicolumn{4}{|c|}{$\begin{array}{l}\text { 式中, } P_{\mathrm{ei}} \text { 为作物有效降水量 }(\mathrm{mm}) ; P_{\mathrm{j}} \\
\text { 为第 } \mathrm{j} \text { 次降雨量 }(\mathrm{mm}) ; P_{\mathrm{ej}} \text { 为第 } \mathrm{j} \text { 次有效降雨 } \\
\text { 量 }(\mathrm{mm}) ; \alpha \text { 为有效利用次数。 } E T_{\mathrm{ci}} \text { 为作物 }\end{array}$}} \\
\hline \multirow{3}{*}{$\begin{array}{l}\text { 白城、 } \\
\text { 通榆 }\end{array}$} & 05.21 & 06.05 & 07.21 & 08.28 & & & & & \\
\hline & - & - & - & - & & & & & \\
\hline & 07.04 & 07.21 & 08.28 & 09.20 & & & & & \\
\hline \multirow{3}{*}{$\begin{array}{l}\text { 长春、 } \\
\text { 四平 }\end{array}$} & 05.15 & 06.03 & 07.21 & 08.31 & & \multirow{2}{*}{\multicolumn{4}{|c|}{$\begin{array}{l}\text { 需水量 }(\mathrm{mm}) ; \mathrm{i} \text { 为各生育阶段, } E T_{0} \text { 为FA0 } 56 \\
\text { 推荐的Penman-Monteith (P-M) 模型计算的 }\end{array}$}} \\
\hline & - & - & - & - & & & & & \\
\hline & 07.03 & 07.21 & 08.31 & 09.21 & & \multicolumn{4}{|c|}{ 参考作物蒸散发 $(\mathrm{mm} / \mathrm{d})$ 。本文采用北方春 } \\
\hline \multirow{3}{*}{ 乾安 } & 05.21 & 06. 17 & 07.31 & 08.21 & & \multicolumn{4}{|c|}{ 玉米干旱等级标准 ${ }^{[13]}$ 中规定的水分亏缺指 } \\
\hline & - & - & - & - & & \multirow{2}{*}{\multicolumn{4}{|c|}{ 数干旱等级划分, 确定基于玉米水分亏缺指 }} \\
\hline & 07.19 & 07.31 & 08.21 & 09.25 & & \multirow{2}{*}{\multicolumn{4}{|c|}{ 数的干旱等级标准，见表2[13]。 }} \\
\hline \multirow{3}{*}{ 前郭 } & 05.19 & 06. 13 & 07.21 & 08.23 & & & & & \\
\hline & - & - & - & - & \multicolumn{5}{|c|}{ 表 2 玉米干旱等级划分表 } \\
\hline & 07.13 & 07.21 & 08.23 & 09. 20 & 干 & \multirow{4}{*}{$\begin{array}{c}\text { 出苗-拔 } \\
\text { 节 }\end{array}$} & \multirow{4}{*}{$\begin{array}{c}\text { 拔节-抽 } \\
\text { 雄 }\end{array}$} & \multirow{4}{*}{$\begin{array}{c}\text { 抽雄-乳 } \\
\text { 熟 }\end{array}$} & \multirow{4}{*}{ 乳熟-成熟 } \\
\hline \multirow{3}{*}{ 长岭 } & 05.18 & 06.12 & 07.26 & 08.24 & 旱 & & & & \\
\hline & - & - & - & - & 等 & & & & \\
\hline & 07.12 & 07.26 & 08.24 & 09.23 & 级 & & & & \\
\hline \multirow{3}{*}{ 扶余 } & 05.19 & 06.11 & 07.23 & 08.21 & 轻 & \multirow[t]{2}{*}{$(50,65]$} & \multirow[t]{2}{*}{$(35,50]$} & \multirow[t]{2}{*}{$(35,45]$} & \multirow[t]{2}{*}{$(50,60]$} \\
\hline & - & - & - & - & 旱 & & & & \\
\hline & 07.11 & 07.23 & 08.21 & 09.21 & 中 & \multirow{2}{*}{$(65,75]$} & \multirow{2}{*}{$(50,60]$} & \multirow{2}{*}{$(45,55]$} & \multirow{2}{*}{$(60,70]$} \\
\hline & 05.14 & 06.06 & 07.22 & 08.11 & 旱 & & & & \\
\hline \multirow[t]{2}{*}{ 双辽 } & - & - & - & - & 重 & \multirow{2}{*}{$(75,85]$} & \multirow{2}{*}{$(60,70]$} & \multirow{2}{*}{$(55,65]$} & \multirow{2}{*}{$(70,80]$} \\
\hline & 07.06 & 07.22 & 08.11 & 09.03 & 旱 & & & & \\
\hline
\end{tabular}

\section{3. 研究方法}

\section{1 水分亏缺指数及干旱分级方法}

为了更好地反映玉米生长季各生育阶 段的水分需求情况, 本文根据作物需水量和 有效降水量构建水分亏缺指数 (CWDI), 用以 表征玉米的水分亏缺程度 [12]。

$$
\begin{gathered}
C W D I_{i}= \begin{cases}1-\frac{P_{e i}}{E T_{c i}} & E T_{c i} \geq P_{e i} \\
0 & E T_{c i}<P_{e i}\end{cases} \\
P_{\mathrm{ei}}=\sum_{\mathrm{j}=1}^{\mathrm{n}} P_{\mathrm{ej}} \\
P_{\mathrm{ej}}=\alpha_{\mathrm{j}} \cdot P_{\mathrm{j}} \\
E T_{c}=K_{\mathrm{c}} \cdot E T_{0}
\end{gathered}
$$
)

$E T_{0}=\frac{0.408 \Delta\left(R_{n}-G\right)+\gamma \frac{900}{T_{\text {mean }}+273} U_{2}\left(e_{s}-e_{a}\right)}{\Delta+\gamma\left(1+0.34 U_{2}\right)}(5)$ 式中, $P_{\mathrm{ei}}$ 为作物有效降水量 $(\mathrm{mm}) ; P_{\mathrm{j}}$ 为第 $\mathrm{j}$ 次降雨量 $(\mathrm{mm}) ; P_{\mathrm{ej}}$ 为第 $\mathrm{j}$ 次有效降雨 量 $(\mathrm{mm}) ; \alpha$ 为有效利用次数。 $E T_{\mathrm{ci}}$ 为作物 需水量 $(\mathrm{mm}) ; \mathrm{i}$ 为各生育阶段, $E T$ 为FA0 56 玉米干旱等级标准 ${ }^{[13]}$ 中规定的水分亏缺指 


\section{2 相关性分析}

本研究采用 Pearson 相关性分析方法, 对研究区玉米干旱现象和产量进行相关性 的特征分析。

\section{3 结果表达}

本文采用 ARCGIS 软件中的反距离加权 插值法 (IDW) 对各站点统计量进行空间插 值和分类，得到相应的空间分布图。

\section{4. 结果分析}

\section{1 有效降水量、水分亏缺指数时间变化}

采用线性趋势分析法, 对研究区 9 个农 业气象站 1960-2014 年间有效降水量和水分 亏缺指数进行研究, 结果如图 2 所示。出苗 -拔节期, 有效降水量和水分亏缺指数变化 浮动较大, 有效降水量最高值和最低值分别 为 $76.2 \mathrm{~mm}, 1.9 \mathrm{~mm}$, 分别位于 1977 年和 2004 年, 在 80 年代以后水分亏缺指数上升浮动 较大, 多超过 50\%, 其中在 80, 90, 00 年代中 期, 水分亏缺指数达到 $80 \%$ 以上, 为极干旱 年, 在该生育期。拔节一抽雄期, 水分亏缺 指数和有效降水量的多年变化趋势比较平 稳, 变化不显著, 水分亏缺最高值为 1997 年, 达到 $86 \%$, 据统计该年吉林中西部地区 发生了严重干旱情况。抽雄-乳熟阶段, 水 分亏缺指数呈不明显的下降趋势, 该年水分 亏缺指数较低, 拒灾害大典记载, 该年当地 发生多次暴雨事件, 除此之外全区整体呈干 旱趋势; 乳熟一成熟阶段, 全区水分亏缺指 数多在 $50 \%$ 以上, 干旱现象较为严重, 与当 地秋旱的频发现象比较吻合, 该生育期的突 变年发生在 1992 年。纵观整个生长季, 吉 林中西部地区受旱影响较为明显。
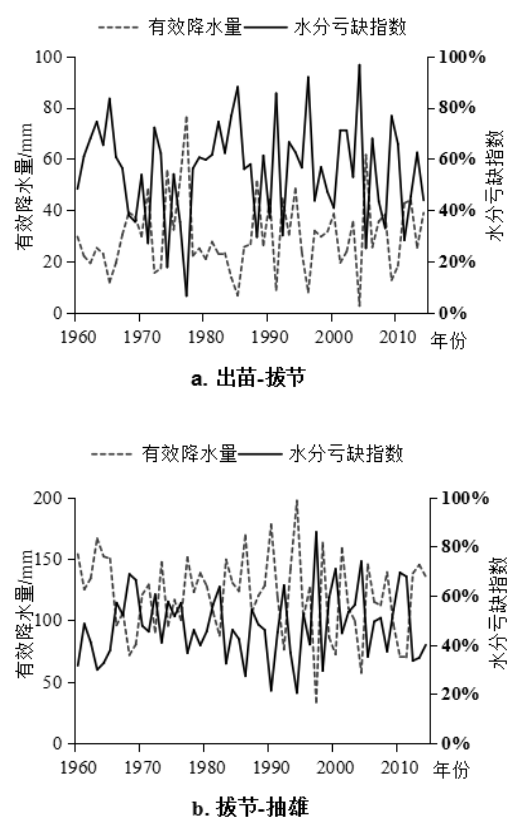

--.- 有效降水量——水分亏缺指数

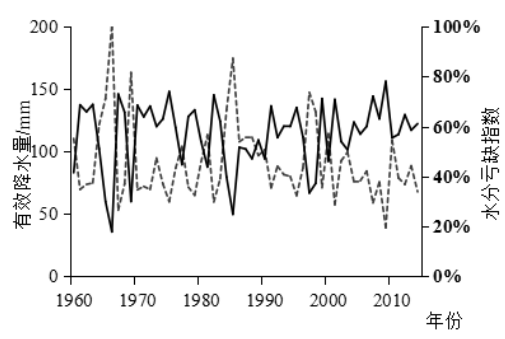

c. 抽雄-乳熟

----- 有效降水量——水分亏缺指数

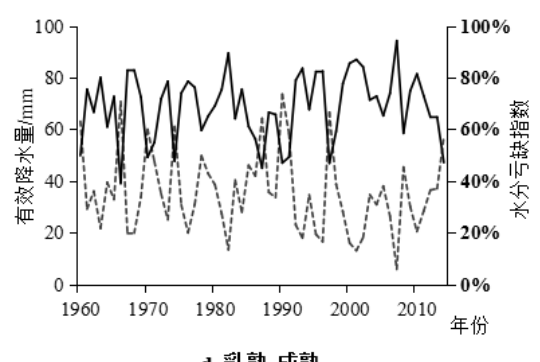

图 2 吉林中西部玉米 1960-2014 年不同生 育期有效降水量和水分盈亏指数变化情况 


\section{2 吉林中西部玉米生长季干旱频率特征}

本文通过干旱等级标准 (表 2) 计算各 生育阶段发生不同干旱程度的频率, 并统计 玉米四个不同生育期轻旱、中旱、重旱的频 率 (图 3)。出苗-拔节期, 发生轻旱的频率 总体上由西向东部地区递增, 最高值位于双 辽市; 发生重旱的频率除南部几个地区较高 外, 普遍较低; 发生重旱频率由西部向东部 地区递增, 其中通榆、白城最高, 这说明在 出苗-拔节期东部地区旱情较为严重。拔节抽雄期, 发生轻旱、重旱均有又东向西递减 的趋势, 四平市发生重旱频率较高; 抽雄乳熟期, 除四平、公主岭、梨树县发生轻、 重旱频率较高外, 其余地区频率约在 5\%-15\% 之间, 白城市发生重旱频率较高, 约达 $27 \%$; 乳熟一成熟期, 发生轻、中和重旱的地区差 异性较大, 发生轻旱的频率较低, 在 5\%-15\% 之间, 且西部较东部更旱, 中部地区发生中 旱的频率较高, 东西两侧旱情相对轻, 该生 育阶段发生重旱的频率由西部向东部递增。
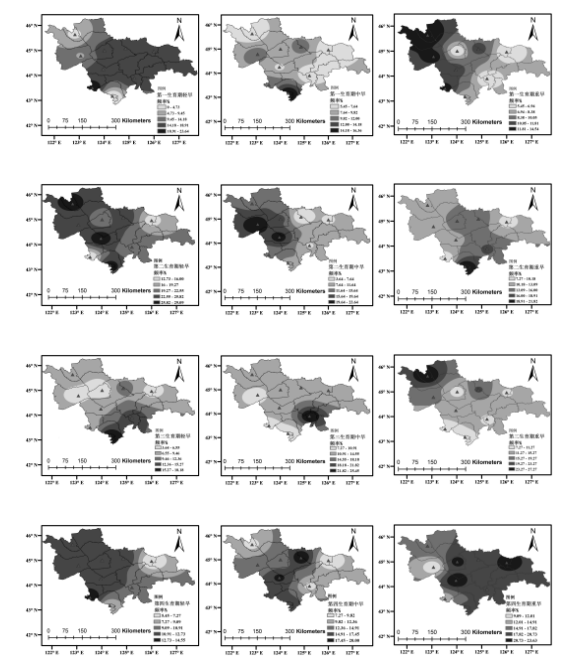

图 3 吉林中西部玉米不同生育阶段干早频 率分布

\section{3 研究区玉米生长季干旱对产量的影响}

本文采用 1961-2014 年间不同站点各个 生育期的水分亏缺指数和所对应站点当年 的单产进行相关性分析, 得出如图 4 所示结
果。在出苗-拔节期, 在研究区的西部和东 南部地区水分亏缺指数与当地玉米单产呈 正相关关系, 也就是说在该生育期东南和西 部地区的旱情对产量的影响不大, 但中部地 区水分亏缺指数与当地玉米单产呈负相关 关系, 会造成减产的影响; 拔节-抽雄期, 空间分布与第一生育期差异性较大, 除零星 几个站点呈正相关关系外, 大部分地区均呈 负相关关系, 这说明在该生育期大部分地区 受早后易造成玉米的减产; 在抽雄到乳熟和 乳熟-成熟时期, 研究区中北部和南部地区 玉米产量易于受到旱情的影响, 其余地区受 旱影响不大。
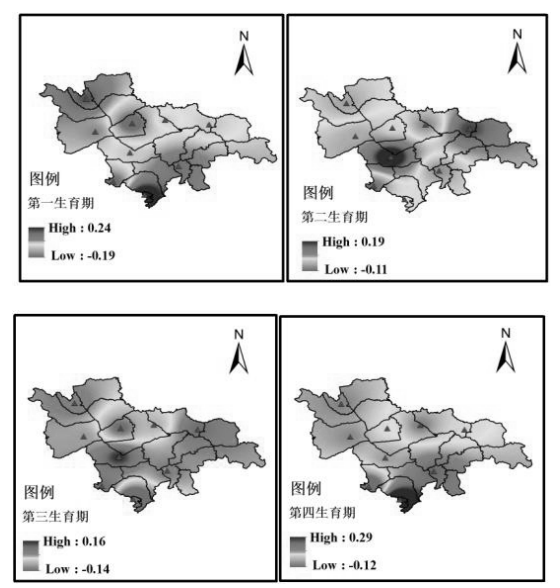

图 4 吉林中西部玉米不同生育期水分亏缺 指数与产量的相关性分布

\section{5. 结论}

本文以吉林省中西部为例, 基于 1960-2014 年气象数据构建水分亏缺指数, 分生育阶段划分玉米干旱等级, 并结合相应 年份的玉米单产数据对其相互关系进行分 析和研究, 得到如下结论:

（1）出苗-拔节阶段玉米水分亏缺指数 有逐渐下降的趋势; 拔节-抽雄和抽雄-乳熟 阶段玉有效降水量和水分亏缺指数整体变 化较为稳定; 乳熟一成熟阶段有效降水量和 水分亏缺指数波动较大, 旱情比较严重。全 区整体为水分亏缺状态, 该地区旱情严重。

（2）出苗-拔节阶段为作物发育前期, 吉林西部较西部地区干旱现象更为严重; 拔 节-抽雄阶段, 水分亏缺指数东侧旱情更为 
严重; 抽雄-乳熟阶段, 梨树、四平等地无 旱, 其余旱情严重; 乳熟一成熟阶段, 水分 亏缺指数最大, 全区均较为干旱。综合四个 生育期, 可以看出, 西部地区更易发生春旱, 且旱情较为严重, 东部地区更易发生秋旱。

(3) 在四个生育阶段, 研究区北部地 区的水分亏缺指数和产量呈现较为明显的 负相关关系，北部地区受到干旱后对玉米产 量有直接的影响, 除拔节-抽雄期外, 其余 三个生育期东部地区的水分亏缺指数与玉 米产量呈正相关关系, 对玉米产量的影响不 大。

\section{Acknowledgments}

This study was supported by National Science Foundation of China (41571491 and 41371495); The China Special Fund for Meteorological Research in the Public Interest (GYHY201506001-6); The National Key Technology R\&D Program of China under Grant (2013BAK05B01); The Fundamental Research Funds for the Central Universities of China (2412016KJ046).

\section{致谢}

本研究得到了国家自然科学基金项目 （41571491 和 41371495)、公益性行业（气 象）科研重大专项 (GYHY201506001-6)、国 家重点技术研发项目（2013BAK05B01）、中 央高校基本科研业务费专项资金资助 (2412016KJ046)

\section{参考文献}

[1] Zipper S C, Qiu J, Kucharik C J. Drought effects on US maize and soybean production: spatiotemporal patterns and historical changes, Environmental Research Letters, 2016, 11(9): 094021.

[2] Guo S J. The meteorological disaster risk assessment based on the diffusion mechanism, Journal of Risk Analysis and Crisis Response, 2012, 2(2): 124-130.

[3] 刘宪锋, 朱秀芳, 潘耀忠, 等, 农业干旱
监测研究进展与展望, 地理学报, 2015, 70(11): 1835-1848.

[4] Wang X D. The Analysis on the Effecting Factor of Drought Disease in Qingyang, Gansu, Journal of Risk Analysis and Crisis Response, 2016, 6(2): 103-108.

[5] 王春乙, 张继权, 霍治国, 等, 农业气象 灾害风险评估研究进展与展望, 气象学 报, 2015, 1-19.

[6] 薛昌颖, 张弘, 刘荣花, 黄淮海地区夏玉 米生长季的干旱风险, 应用生态学报, 2016, 27(5): 1521-1529.

[7] 胡亚南, 华北冬小麦一夏玉米轮作区干 旱灾害风险评估, 中国农业科学院博士 学位论文, 2013.

[8] 刘泓志, 肖长来, 张岩祥, 等, 吉林省西 部 52 年降水量分布演变特征及趋势分 析, 水电能源科学, 2015, (6): 11-14.

[9] Rahman M R, Lateh H. Meteorological drought in Bangladesh: assessing, analysing and hazard mapping using SPI, GIS and monthly rainfall data, Environmental Earth Sciences, 2016, 75(12): 1-20.

[10] Xiao J, Huo Z, Huang D, et al, Meteorological Grading Indexes of Water-saving Irrigation for Corn, Journal of Risk Analysis and Crisis Response, 2013, 3(2): 95-102.

[11] 黄生志, 黄强, 王义民,等, 基于 SPI 的 渭河流域干旱特征演变研究, 自然灾害 学报, 2015, 15-22.

[12] 张玉芳, 王明田, 刘娟, 等, 基于水分 盈亏指数的四川省玉米生育期干旱时 空变化特征分析, 中国生态农业学报, 2013, 21(2): 236-242.

[13] 中国气象局, 北方春玉米干旱等级, 北 京: 中国气象出版社, 2015. 